Review paper

\title{
Higher patient doses through X-ray imaging procedures
}

\author{
Madan M. Rehani ${ }^{\text {a,*, David Nacouzi }}{ }^{\mathrm{b}}$ \\ ${ }^{\mathrm{a}}$ Massachusetts General Hospital, Boston, MA 02114, USA \\ ${ }^{\mathrm{b}}$ Duke University Medical Center, Durham, NC 27708, USA
}

\section{A R T I C L E I N F O}

\section{Keywords:}

Computed tomography (CT) doses

High doses medical imaging

Cumulative radiation doses

Effective dose

Interventional procedures

\begin{abstract}
A B S T R A C T
Medical imaging using X-rays has been one of the most popular imaging modalities ever since the discovery of Xrays 125 years ago. With unquestionable benefits, concerns about radiation risks have frequently been raised. Computed tomography (CT) and fluoroscopic guided interventional procedures have the potential to impart higher radiation exposure to patients than radiographic examinations. Despite technological advances, there have been instances of increased doses per procedure mainly because of better diagnostic information in images. However, cumulative dose from multiple procedures is creating new concerns as effective doses $>100 \mathrm{mSv}$ are not uncommon. There is a need for action at all levels. Manufacturers must produce equipment that can provide a quality diagnostic image at substantially lesser dose and better implementation of optimization strategies by users. There is an urgent need for the industry to develop CT scanners with sub-mSv radiation dose, a goal that has been lingering. It appears that a new monochromatic X-ray source will lead to replacement of X-ray tubes all over the world in coming years and will lead to a drastic reduction in radiation doses. This innovation will impact all X-ray imaging and will help dose reduction. For interventional procedures, the likely employment of robotic systems in practice may drastically reduce radiation exposures to operators- but patient exposure will still remain an issue. Training needs always need to be emphasized and practiced.
\end{abstract}

\section{Introduction}

Since their discovery 125 years ago, X-rays have been at the core of some of the most popular imaging modalities in medicine. This is evident from the 3.6 billion X-ray exams that were performed annually worldwide according to the 2008 United Nations Scientific Committee on Effects of Atomic Radiation (UNSCEAR) report [1]. Current estimates are not yet available from UNSCEAR, but it is expected that between 4 and 5 billion X-ray exams are performed annually across the globe, implying that nearly 13 million imaging exams every single day of the year are performed using X-rays. No other medical imaging modality matches this level of use. While the utility of X-rays in diagnosis, followup, and management of many diseases (through interventional guidance) has been unquestionable, concern about radiation risks have frequently been raised [2-4]. Concerns regarding radiation risk have centered on both tissue reactions (earlier called deterministic effects) and stochastic effects $[5,6]$. These concerns have led to improvements in imaging technology and the proposal of a variety of solutions to optimize and justify the use of X-rays in medical imaging $[2,7,8]$.

Despite being the most frequent imaging modality, radiography involves a relatively small radiation dose per exam, typically ranging from a fraction of a mSv of effective dose $(E)$ to $3 \mathrm{mSv}$. Furthermore, the dose in radiographic examination has decreased by nearly an order of magnitude in the last half a century, as shown in Table 1 which was taken from an earlier paper [2]. However, some computed tomography (CT) and interventional procedures using fluoroscopy are associated with a relatively higher E (a few tens of $\mathrm{mSv}$ ). This and increasing patient radiation doses are primarily due to many fold increases in diagnostic information [9]. Previously, in 1970's, the CT scan used to be 10 $\mathrm{mm}$ slices scan with about $10 \mathrm{~mm}$ inter-slice gap. Now there are increasingly thinner and thinner slices and volume scanning with no gap thus giving images that have much more information so as not to miss a lesion or abnormality in the body [10]. The cost of this increased information is increased radiation dose. Per exam, dose in CT has varied from about a mSv to about $15 \mathrm{mSv}$. Recent studies have shown that with the use of multiphase CT imaging and recurrent imaging, much higher doses are being received by some patients $[11,12]$, as discussed later. Also, the use of CT for performing interventions has led to as much as $100 \mathrm{mSv}$ in a single procedure [13]. Relatively high doses both in CT and interventional procedures are becoming a focus of recent attention.

\footnotetext{
* Corresponding author at: Radiology Department, Massachusetts General Hospital, 175 Cambridge Str., Suite 244, Boston, MA 02114, USA.

E-mail addresses: madan.rehani@gmail.com, mrehani@mgh.harvard.edu (M.M. Rehani).
} 
Table 1

Trends in average effective doses resulting from selected diagnostic medical examinations in countries in Health Care Level 1, as per UNSCEAR data [1,2].

\begin{tabular}{lllll}
\hline \multirow{2}{*}{ Examination } & \multicolumn{4}{l}{ Average effective dose per examination in millisieverts in years } \\
\cline { 2 - 5 } & $1970-1979$ & $1980-1990$ & $1991-1996$ & $1997-2007$ \\
\hline Chest radiography & 0.25 & 0.14 & 0.14 & 0.07 \\
Abdominal X-ray & 1.9 & 1.1 & 0.53 & 0.82 \\
Mammography & 1.8 & 1 & 0.51 & 0.26 \\
CT scan & 1.3 & 4.4 & 8.8 & 7.4 \\
Angiography & 9.2 & 6.8 & 12 & 9.3 \\
\hline
\end{tabular}

This paper being part of the 125th year celebration of discovery of $\mathrm{X}$ rays by Roentgen, the paper deals only with doses from X-ray procedures and thus excludes nuclear medicine studies.

\section{Dosimetric quantities}

For stochastic risks, E is the most appropriate quantity to date [14]. One must distinguish between dose per exam, collective dose, and cumulative dose as otherwise it leads to confusion. Dose per exam is rather easy to understand if one confines oneself to a single dose quantity. Medical physicists can use dozens of metrics to infer dose, starting from machine related operating parameters like, mAs and indirectly $\mathrm{kVp}$ as the minimum, then going to $\mathrm{CTDI}_{\mathrm{vol}}$, dose length product (DLP), size specific dose estimates (SSDE) and finally effective dose (E). There are several dose quantities for different imaging modalities that have been agreed upon by ICRU and IAEA $[15,16]$. They range from description of machine output to dose at the entrance of the patient, to organ doses and to finally the effective dose (E). None of these quantities are perfect as they each pertain to a small piece of what we need for holistic dose information. Physicians obviously get confused if presented with such a number of different dose metrices. Thus, despite the limitations of $\mathrm{E}$, it remains the best single descriptor and has been used the most despite being the most argued quantity [14]. E was initially derived for a standard/ reference sized person, and newer developments are suggesting patient-specific E [14]. In future, if a better alternative becomes available, things may be different.

The average dose per exam (commonly expressed in E) when multiplied by population provides collective dose to the population (as person-sievert) and has been used extensively by organizations dealing with population dose such as UNSCEAR, European Commission, and many national organizations. In this review paper, we will focus on protection of the individual rather than the population and thus will not deliberate further on collective doses. For the individual patient, the cumulative dose, which is the sum of doses from different exams, is used. Once again, this becomes feasible mainly with E. When the sum of effective doses from CT exams for example, is done, then it becomes the cumulative effective dose (CED) $[12,17]$. For interventional procedures, kerma-area-product (KAP) and estimation of E using appropriate coefficients is practiced to indicate stochastic risk. Peak skin dose is the most appropriate dose quantity for tissue reactions, but an inability to have electronic peak skin dose estimate available in most fluoroscopy machines precludes the use of this quantity. Kerma at the interventional reference point (Ka,r) is thus far the most easily available dose metric in angiography machines and most recommendations for tissue reactions are based on Ka,r.

\section{High doses in CT}

The development and implementation of multidetector-row computed tomography (MDCT) in the 1990's represented a significant evolution in CT $[18,19]$. As opposed to the previous generation of CT's with a single-detector-row (SDCT), the MDCT's rotate-rotate approach with expanded detector arrays allowed for volumetric acquisition of entire organs. These could be performed with high spatial resolution and within the time of a single breath hold, at least for chest CT. This provided many benefits, including reduced motion-based artifacts (common in children, trauma patients, or cardiac imaging), decreased quantity of required contrast medium (thus reducing potential kidney damage), and thinner slice acquisition. MDCT however represented a trade-off between enhanced diagnostic capability and increased radiation exposure for increased information. This compromise can be seen in the comparison of SDCT and MDCT doses in Table 2.

A number of contributing factors have identified why MDCT scanners are prone to delivering higher radiation doses to patients. These include the existence of dose inefficiencies in early 4-MDCT systems, actions that lead to higher doses to address image noise in thinner slices during 3D imaging of thinner slices, and a newfound ease in acquiring greater scan volumes and multiple contrast phases. On the technical side, unnecessarily high patient dose occurred in part due to overbeaming (beam geometries larger than the detector width), comparably shorter X-ray source-to-patient distance, and overlapping beams. In addition, the MDCT's use of narrow collimation caused a decrease in geometric efficiency and thus an increase in image noise and was countered through the use of increased dose [19]. Use of higher than needed image quality, with a preference for crisp images rather than those with some noise present, has also contributed to the higher CT doses $[9,20]$. As such, radiologists must be willing to use images with some noise (salt and pepper appearance) [20].

There are limited clinical studies demonstrating change in patient dose for a defined exam. A longitudinal analyses of radiation dose data was undertaken on adult patients undergoing repeat identical and clinically indicated thoracoabdominal CT examinations [21]. The investigators noted trend toward global reduction in size specific dose estimates (SSDE) values, despite widespread variations in the radiation dose absorbed by each patient undergoing identical repeat thoracoabdominal CT protocols.

In another study, 1695 paediatric chest CT examinations conducted over 7 years were analyzed [22]. The median volume CT dose index (CTDI; mGy), effective dose (E; mSv) and size-specific dose estimate (SSDE; $\mathrm{mGy}$ ) were investigated in the different years of the observation time and decrease was demonstrated through regression curves. Although it is difficult to state how much percent change in radiation dose has actually occurred, scattered reports indicate changes in clinical settings largely under controlled observations during the past two decades. The observations are also available from ACR Dose Index Registry (ACR-DIR) but there is lack of a cohesive reporting to demonstrate quantitatively the magnitude of change.

For many years, the focus in radiation doses from CT exams has been placed on individual exam dose, which has been decreasing substantially over the years [9]. For example, the drastic increase in computational power since the 1970 's has allowed a switch from filtered back projection to iterative reconstruction of CT images in CT systems worldwide. In these systems, the noise reduction facilitated by iterative

Table 2

Effective doses for various CT examination using single detector CT (SDCT) and multi-detector (MDCT) systems, taken from ICRP P102 [19].

\begin{tabular}{lcc}
\hline Examinations & Effective dose (mSv) SDCT & Effective dose (mSv) MDCT \\
\hline Abdomen and pelvis & 17.2 & 14.4 \\
Liver/kidney & 8.7 & 11.5 \\
Aorta, abdominal & 7.6 & 10.3 \\
Coronary CTA & - & 10.5 \\
Brain & 2.8 & 2.8 \\
Face and sinuses & 1.1 & 0.8 \\
Face and neck & 2.0 & 2.0 \\
Chest & 6.2 & 5.7 \\
Pelvis & 8.8 & 7.2 \\
Aorta, thoracic & 5.8 & 6.7 \\
Pulmonary vessels & 3.6 & 5.4 \\
Cervical spine & 2.1 & 2.9 \\
Lumbar spine & 2.7 & 8.1 \\
\hline
\end{tabular}


reconstruction has allowed patient dose reductions of $26-50 \%$ per exam compared to traditional filtered back projection systems [23]. Meanwhile, dual-energy CT has allowed improved image quality per dose over traditional systems by utilizing two different tube potentials to provide increased CNR with comparable dose [24]. Not only have these technologies allowed for reduced dose per exam when used alone, they have also facilitated an improved diagnostic ability when performing dedicated low-dose CT exams via modulation of tube current, potential, or pitch [25].

Despite these advances in per-exam dose, cumulative doses to individual patients have reached such a high level that radiation risks can no longer be ignored $[12,17,26,27]$. A large study on 2.5 million patients who underwent 4.8 million CT exams found that $1.33 \%$ of patients received CEDs $\geq 100 \mathrm{mSv}$ with an overall median CED of $130.3 \mathrm{mSv}$, and a maximum of $1185 \mathrm{mSv}$ during a period between 1 and 5 years [12]. Although the vast majority (72-86\%) of patients were $>50$ years of age, nearly $20 \%$ ( 13.4 to $28 \%$ ) were $\leq 50$ years. The paper concluded that we are in an unprecedented era where patients undergoing multiple CT exams during a short span of 1 to 5 years are not uncommon and a sizable fraction among them are below 50 years of age. The investigators further reported their results from a single institution and found that $9.6 \%$ of patients exhibited non-malignant conditions, with $1.4 \%$ of the patients $\leq 40$ years old [26]. More than half of the CT exams were unrelated to follow-up of a primary chronic disease. Imaging guidelines and appropriateness use criteria are not available for many conditions, however, this study identified many of them. Wherever guidelines are available, they tend to be for initial work-up and diagnosis. As such, there is a lack of guidance on serial CT imaging. These studies thus provide characteristics of the population of patients with CED $\geq 100$ mSv.

Further, the minimum time to accrue $100 \mathrm{mSv}$ was a single day at all four institutions included in the study. This had been previously unreported prior to this author's finding in 2019 [12].

The most important message of these papers was that there is an urgent need for the industry to develop CT scanners with sub-mSv radiation dose, a goal that has been lingering $[7,12,26]$.

In another study, the authors estimated the number of patients receiving high doses in 35 OECD (Organization for Economic Cooperation and Development) countries [17]. They found patients receiving CED $\geq 100 \mathrm{mSv}$ amounted to $0.21 \%$ of the population. Expressed as per 1000 population, the values ranged from 0.51 for Finland to 2.94 for the US, a nearly six-fold difference. Countries with $>2$ patients with CED $\geq 100 \mathrm{mSv}$ in a 5 -yr period per 1000 population were: Belgium, France, Iceland, Japan, Korea, Luxembourg, Portugal, Turkey, and US.

\section{Tracking and assessment of high doses in different disease conditions}

The review of the various aspects involved in tracking a patient's radiation exposure to obtain a lifelong record of radiation dose of individual patient is available [28]. Description of how tracking has helped the process of justification and optimization was done by taking the case reports in the day-to-day setting of a paeditric hospital [29]. For a

Table 3

Cumulative radiation exposure and patients with CED $>100 \mathrm{mSv}$ [27].

\begin{tabular}{|c|c|c|c|c|c|c|c|}
\hline Author & Condition & N. Pts & $\mathrm{X}$-ray procedures & $\begin{array}{l}\text { Age (years) Mean or } \\
\text { Median } \S\end{array}$ & $\begin{array}{l}\text { Patients with CED } \\
>50 \mathrm{mSv}\end{array}$ & $\begin{array}{l}\text { Patients with CED } \\
>100 \mathrm{mSv}\end{array}$ & $\begin{array}{l}\text { Follow-up } \\
\text { (years) }\end{array}$ \\
\hline Chen 2010 [81] & Pts with Cardiac Imaging & 90,121 & Only Cardiac Procedures & 51.1 & $3173(3.5 \%)^{\#}$ & $75(0.08 \%)^{\wedge}$ & 3 \\
\hline $\begin{array}{l}\text { Einstein } 2010 \\
\quad[82]\end{array}$ & $\begin{array}{l}\text { Pts with myocardial } \\
\text { perfusion scan }\end{array}$ & 1097 & All medical imaging procedures & 62.2 & & $344(31.4 \%)$ & 20 \\
\hline Stein 2010 [83] & Cardiac disease & 8656 & All medical imaging procedures & 65.9 & $533(6.2 \%)$ & & 3 \\
\hline Kaul $2010[84]$ & $\begin{array}{l}\text { Acute myocardial } \\
\text { infarction }\end{array}$ & 64,071 & All medical imaging procedures & $64.9 \S$ & $1060(1.7 \%)^{\circ}$ & & - \\
\hline $\begin{array}{l}\text { Eisenberg } 2011 \\
\text { [85] }\end{array}$ & $\begin{array}{l}\text { Acute myocardial } \\
\text { infarction }\end{array}$ & 82,861 & Only Cardiac Procedures & $63.2 \S$ & $15,090(18 \%)^{*}$ & & 1 \\
\hline $\begin{array}{l}\text { Lawler } 2011 \\
\quad[86]\end{array}$ & $\begin{array}{l}\text { Acute myocardial } \\
\text { infarction }\end{array}$ & 11,427 & Only Cardiac Procedures & $68.0 \S$ & $825(7.2 \%)^{* \circ}$ & & 1 \\
\hline $\begin{array}{l}\text { Kinsella } 2010 \\
\text { [87] }\end{array}$ & Hemodialysis & 100 & All medical imaging procedures & 58.9 & $26(26 \%)$ & $13(13 \%)^{*}$ & 3.4 median \\
\hline $\begin{array}{l}\text { De Mauri } 2011 \\
\quad[88]\end{array}$ & Hemodialysis & 106 & All medical imaging procedures & 65.3 & & $17(16 \%)$ & 3.0 median \\
\hline \multirow{2}{*}{$\begin{array}{l}\text { Coyle } 2011 \\
{[89]}\end{array}$} & Hemodialysis & 244 & All medical imaging procedures & 52.7 & $56(23 \%)$ & & \multirow[t]{2}{*}{4.0 median } \\
\hline & Kidney Transplant & 150 & All medical imaging procedures & 45.7 & $12(8 \%)$ & & \\
\hline $\begin{array}{l}\text { De Mauri } 2012 \\
\quad[90]\end{array}$ & Kidney Transplant & 92 & All medical imaging procedures & 52.4 & $26(28 \%)$ & $11(12 \%)$ & 4.1 median \\
\hline 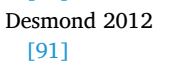 & Crohn's & 354 & All medical imaging procedures & 32 & & $55(16 \%)^{*}$ & 15 \\
\hline \multirow[t]{2}{*}{ Levi 2009 [92] } & Crohn's & 199 & \multirow{2}{*}{$\begin{array}{l}\text { All medical imaging procedures } \\
\text { (no Interventional) }\end{array}$} & \multirow[t]{2}{*}{39} & \multirow[t]{2}{*}{$23(7 \%)$} & & 5.5 \\
\hline & Ulcerative Colitis & 125 & & & & & 5.0 \\
\hline $\begin{array}{l}\text { Kroeker } 2011 \\
\text { [93] }\end{array}$ & Crohn's & 371 & All medical imaging procedures & 40 & $27(7 \%)$ & $12(3 \%)^{*}$ & 5 \\
\hline 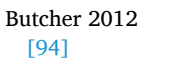 & Crohn's & 127 & All medical imaging procedures ( & 45 & $8(6 \%)$ & & 11.2 \\
\hline Estay 2015 [95] & Crohn's & 82 & All medical imaging procedures & 36 & $16(20 \%)$ & & 9.6 \\
\hline $\begin{array}{c}\text { Chatu } 2013 \\
\text { [96] }\end{array}$ & Crohn's & 217 & All medical imaging procedures & 31 & $29(13 \%)$ & & 8.3 \\
\hline Jung 2013 [97] & Crohn's & 777 & All medical imaging procedures & 29 & $249(35 \%)$ & & 15 \\
\hline $\begin{array}{l}\text { Fuchs } 2011 \\
\text { [98] }\end{array}$ & Crohn's & 171 & All medical imaging procedures & 11 (pediatric) & $14(8 \%)$ & & 5.3 \\
\hline $\begin{array}{l}\text { Sauer } 2011 \\
\text { [99] }\end{array}$ & Crohn's & 86 & All medical imaging procedures & 12 (pediatric) & $6(7 \%)$ & & 3.5 \\
\hline \multirow{3}{*}{$\begin{array}{l}\text { Huang } 2011 \\
\quad[100]\end{array}$} & Crohn's & 61 & \multirow[t]{3}{*}{ All medical imaging procedures } & \multirow[t]{3}{*}{$11 \S$ (pediatric) } & \multirow[t]{3}{*}{$6(6 \%)$} & & \multirow[t]{3}{*}{5} \\
\hline & Ulcerative Colitis & 32 & & & & & \\
\hline & Indeterminate colitis & 12 & & & & & \\
\hline $\begin{array}{l}\text { Brambilla } 2015 \\
\text { [101] }\end{array}$ & EVAR & 71 & All medical imaging procedures & 74 & $71(100 \%)$ & $66(93 \%)$ & 1.8 \\
\hline
\end{tabular}

*CED > $30 \mathrm{mSv}$; \# CED > $60 \mathrm{mSv}$; *CED > 75; ^CED > $150 \mathrm{mSv}$; ${ }^{\circ}$ per admission after acute myocardial infarction; $\S$ Median. 
detailed view of various aspects of tracking, readers are referred to other publications, as those are outside the scope of the current paper [8,30-35].

In the previous years, many studies have reported high cumulative doses to patients not only from CT but other exams as well, and they are reviewed in a recent paper [27]. The results of those papers are summarized here in Table 3, taken from [27]. These high cumulative doses have been discussed in detail across several different categories e.g. cardiac disease, end stage kidney disease, Crohn's disease, Endovascular aortic repair (EVAR) as reviewed in paper [27]. Although publications reviewed in this paper showed that some patients undergoing recurrent radiological procedures can receive CED between 50 - over $1000 \mathrm{mSv}$ or in some cases more, it is unknown whether this was restricted only to these disease categories or widespread among patients overall. To assess the population health aspect of high doses the studies mentioned above $[12,26,27]$ evaluated patients undergoing CT exams at multiple hospitals across several countries.

\section{High doses in interventional procedures}

Interventional procedures attempt to minimize the invasiveness of various medical procedures through application of an assortment of medical imaging guidance. Interventional procedures avoid open surgical procedures by using live imaging modalities, such as fluoroscopy, to guide fine instruments to the target site [36]. While its inception began in the cardiac field, the applicability of interventional procedures now spans the whole of medicine. Given its noninvasive focus and reduced rate of post-operative complications, the use of interventional procedures continues to grow among both patients and providers. Despite a host of modalities available for guidance, the predominant imaging method is fluoroscopy [37].

The US Food and Drug Administration (FDA) stipulates that fluoroscopy equipment provided with automatic exposure rate control (AERC), shall not be operable at any combination of tube potential and current that will result in an air kerma rate exceeding $88 \mathrm{mGy}$ per minute at the measurement point specified in standard [38]. If provided, when a high level mode of operation is activated, the limit is doubled to $176 \mathrm{mGy} / \mathrm{min}$ [38].

Typical dose rates reported for fluoroscopic imaging range from around $17 \mathrm{mGy} / \mathrm{min}$ for thin tissues or small patients, to $44 \mathrm{mGy} / \mathrm{min}$ for more standard tissues and patient sizes [39].

As per National Council of Radiation Protection and Measurements (NCRP) Report 168, a FGI procedure should be classified as a potentiallyhigh radiation dose procedure if $>5 \%$ of cases result in $K_{\mathrm{a}, \mathrm{r}}$ exceeding 3 Gy or $P_{\mathrm{KA}}$ exceeding $300 \mathrm{~Gy} \mathrm{~cm}^{2}$ [40]. Although those patients in the median and lower percentiles undergoing PCI were not imaged with an air kerma quite near the $3 \mathrm{~Gy}$ threshold, they most certainly underwent a variety of pre-procedural diagnostic imaging given their condition.

High doses in interventional procedures are common but the focus has been on tissue reactions and injuries, as injuries have continued to be reported ever since the early 1990's [3,41-44]. There are well established guidelines by various organizations to avoid injuries [40,45-48] including action before, during and after the procedure. Monitoring of kerma at the reference point (Ka,r) is the crucial indicator for possible tissue injury. Most literature on radiation induced skin injury comes from experience with injuries in radiotherapy (high energy X-rays or gamma rays). Thus the precise dose-effect correlation with fluoroscopic $\mathrm{X}$-rays is not established [43,49,50]. Values between 3 and 5 Gy of Ka,r have been used by most organizations and institutions for following up patients, but injuries are rarely observed below $9 \mathrm{~Gy}$ of Ka,r or in some cases even higher. This is so as Ka,r is not skin dose but is cumulative air kerma when the tube may be rotating and operating in different views. The skin dose will vary with position of the tube as dose gets distributed over different parts of the body as the view changes. On the other hand, $\mathrm{Ka}, \mathrm{r}$ is at the fixed reference point. Depending upon thickness of the patient, Ka,r may lie on patient skin, below the skin of a few $\mathrm{cm}$ away from the skin in air towards the X-ray tube. Multiple procedures on the same patient may require higher dose if the gap between procedures is of several weeks. These aspects are discussed at length in other publications and readers are referred to those [49,51-53].

Somehow the emphasis on stochastic risk in interventional procedures has not received adequate attention in the past. It is true that tissue injuries have been observed, they are serious in some patients, and need definite preventive actions as treatment options are either not available or are not easy, but keeping stochastic risks out of considerations is not appropriate. Stochastic risks in interventional procedures have mainly been emphasized in children, in light of their longer life expectancy.

One reason why stochastic risk has not received comparable attention in previous years is that effective dose in interventional procedure has been considered relatively low, around 9-17 $\mathrm{mSv}$ for some of the common interventional procedures [54]. Thus, not even in the most extreme cases was patient dose expected to be near $100 \mathrm{mSv}$. However, a recent paper reviewing all the interventional procedures at a major hospital for the past 9 years [55] found that among 46,491 procedures across 25,253 patients, 1011 patients (4\%) had CEDs of $>100 \mathrm{mSv}$. Thus, the percent of patients exceeding $100 \mathrm{mSv}$ is not small. The median value of the CED in this cohort was $177 \mathrm{mSv}$.

Another common understanding was that these procedures are involving older patients and if the procedures are repeated, they are spaced apart by more than a year. It was pointed out by [55] that the majority (about 90\%) of patients had their procedures within 12 months, and $10.7 \%$ were under 40 years of age. For patients whose age at first procedure was 40 years or younger, the dominant medical disorder was chronic disease of the torso (54.6\%) and the percentage of cancer was low (11.1\%). Thus, it will be wrong to assume that one is dealing primarily with patients of advanced ages and that doses in the range of $100 \mathrm{mSv}$ are only accumulated over a long period. This is despite the fact that overall, for the entire patient cohort receiving $>100$ $\mathrm{mSv}$ (not only those age 40 years or less), medical disorders included cancer (36.7\%), chronic disease of the torso (30.0\%), internal bleeding (24.8\%), trauma (4.6\%), organ transplant $(3.2 \%)$ and cerebrovascular disease $(0.7 \%)$. Thus, trauma rather than cancer was the dominant cause for interventional procedure in younger aged patients.

The above paper rightly highlights that although the benefits of successful diagnosis and therapeutic treatment largely outweigh the aforementioned risks in the palliative care of patients under serious trauma or illness, all risks, including the radiation risk associated with fluoroscopic guided interventional procedures, warrant continued attention.

\section{CT guided interventional procedures}

While many interventional procedures can be performed under fluoroscopic guidance, ultrasound (US) or magnetic resonance imaging (MRI) guidance, many require CT guidance especially for interventions that require access to anatomically challenging locations and those requiring better image quality. Typical examples include: biopsy, drainage, myelography, and ablation $[13,56]$.

Unlike CT fluoroscopy that involves somewhat lower doses, CT guided interventions require much higher doses, sometime delivering as much as $100 \mathrm{mSv}$ or more in a single procedure [13]. In their study, the authors found 33 patients who underwent 37 CT-guided interventions, each resulting in $\geq 100 \mathrm{mSv}$. Procedures included ablations (15), myelograms (8), drainages (7), biopsies (6) and other (1). The dose for individual procedures ranged from 100.2 to $235.5 \mathrm{mSv}$ with mean and median doses of $125.7 \mathrm{mSv}$ and $111.8 \mathrm{mSv}$, respectively. Six patients (18\%) were less than 50 years of age. There are situations when an individual patient may require multiple interventions, each involving over $100 \mathrm{mSv}$ during the period of a few weeks or months. 


\section{Newer technology and impact of technology on radiation doses in interventional procedures}

A number of advancements in fluoroscopy systems have and will allow patient exposures to decrease while maintaining and in many cases even improving the image quality and thus the quality of an intended intervention. Such advancements include electroanatomic 3D mapping systems and nonfluoroscopic magnetic guidance systems, which utilize micro-Tesla strength magnetic fields and specialized mapping catheters to provide interventional catheter localization and guidance (typically done via fluoroscopy), and 3D anatomical reconstruction without any need for ionizing radiation [57,58]. Multiple randomized trials have demonstrated the significant benefits that newer, nonionizing catheter localization systems offer, such as reductions in fluoroscopy time and radiation exposure by $70 \%$ and $83 \%$ respectively [59].

Furthermore, pre-recorded fluoroscopic cine loops may be used in conjunction with a magnetic guidance system to reduce procedure duration by $22 \%$ and interventional exposure by $82 \%$ [60]. However, while the new non-ionizing methods are potentially beneficial options, their cost may be prohibitive to some healthcare systems. Thus, in order to prevent greater disparity between healthcare systems, fluoroscopic advancements that have already shown some significant level of integration are also important to consider. Automatic positioning systems reduce the fluoroscopic time (and thus patient exposure) needed to achieve optimal viewing of relevant anatomies using preset views and collimator configurations [61].

\section{Lack of optimization by user despite better technology}

Despite advancements such as dual-energy sources or digital flat panel detectors that allow potential dose reductions of up to $30-60 \%$ [62], studies increasingly show that these technologies are often being used to acquire images of higher quality than necessary for diagnosis. At the user-level, technologists at many institutions are relied on to select imaging parameters, which introduces a significant amount of variability in image quality and patient exposure [63]. This individual-level variability has been supported by the finding that sites lacking a dedicated medical physicist and specialist imaging team are less likely to use existing "Dose Check" features [63]. The concept of diagnostic reference level has been used to achieve optimization of protection $[64,65]$ despite some concerns about limitation of the concept $[66,67]$. Unfortunately, cases of variable and higher exposure have not been confined to abnormal patient attenuation or nonstandard cases. A recent study [20] examining image quality among the most frequent pediatric CT exams found that $16-40 \%$ of the CT images assessed were of higher than necessary quality acquired with higher settings $(\mathrm{kVp}, \mathrm{mAs})$ leading to higher radiation dose for adequate diagnostic interpretation. Similar issues have also been identified in other studies [68-70] and in fluoroscopy. Despite newer fluoroscopy systems incorporating higher sensitivity flat panel detectors (FPDs) and intentional dose-reduction features such as automatic brightness control (ABC), multiple studies have found no statistically significant reduction in patient doses from the use of FPDs over traditional image intensifiers (IIs) for typical fluoroscopic procedure dose rates (e.g. as in coronary angiography) - 31 Gy $\mathrm{cm}^{2}$ (II) vs $33 \mathrm{~Gy} \mathrm{~cm}^{2}$ (FPD) [71], $31.2 \mathrm{~Gy} \mathrm{~cm}^{2}$ vs $33.4 \mathrm{~Gy} \mathrm{~cm}^{2}$ (FPD) [72], and $30 \mathrm{~Gy} \mathrm{~cm}^{2}$ (II) vs $31 \mathrm{~Gy} \mathrm{~cm}^{2}$ (FPD) [73]. Additionally, no significant differences in image quality between a FPD and II in the fluoroscopy mode $(p=0.26)$ were found [71], and that in cinegraphy mode, where the FPD did exhibit intrinsically superior performance over the II exposure settings, were instead programmed for optimized image quality over reduced patient dose. While these exposure parameters can be changed to accomplish the user's objective, operators' uncertainty in how to balance image quality and dose makes them reluctant to adjust these parameters outside of their default values.

Beyond the user-level, important obstacles have been identified at the organization level by personnel responsible for oversight of radiation dose optimization, including resistance to change, limited resources, complex organizational structure, and variations in CT equipment and protocol [74].

\section{Future directions}

The greatest hope on patient dose management always remains from technology that continues to improve and of course actions at the level of users and operators play important role [2,7,75-77]. There is an urgent need for the industry to develop CT scanners with sub-mSv radiation dose, a goal that has been lingering [12]. The upcoming technological advances in CT technology are listed in recent papers $[7,75]$. They essentially fall in 6 categories: More powerful X-ray tubes, thicker prefilters, in a filter changer; use of tunable tube voltage settings; AEC not only to include $\mathrm{mA}$ modulation but also $\mathrm{kV}$ and filter thickness modulation; adaptive bow-tie filters; photon counting detector technology and use of deep learning $[7,75]$. One of the important advances that is coming up is that of monochromatic X-ray source [Silver E, Shulman S, Rehani MM. A New Compact Source of Monochromatic XRays for High Quality, Low Dose, Medical Imaging, under publication]. It appears that this advance will lead to replacement of X-ray tubes all over the world in coming years and will lead to drastic reduction in radiation doses as only X-ray energies that are needed for image formation shall be generated by the X-ray tube and others that unnecessarily add to radiation dose (despite filtration) will be avoided. This innovation will impact all X-ray imaging not only CT and thus will help dose reduction in interventional fluoroscopy as well. For interventional procedures, robotic systems are likely to be implemented into practice which may drastically reduce radiation exposures to operators, but patient exposure will still remain an issue [78]. On the contrary, this may result in complacency on the part of operator resulting in higher patient doses [79]. The operator dose can be reduced by as much as $95 \%$ as the operator navigates the catheter sitting away from the X-ray source at a console either located in a lead shielded cabin in the room or outside the room at usual console. Training needs are perpetual and this always needs to be emphasized and practiced [80].

\section{References}

[1] United Nations Scientific Committee on the Effects of Atomic Radiation (UNSCEAR). 2008 Report to the General Assembly: Annex B Exposures of the Public and Workers from Various Sources of Radiation. vol. I. 2010.

[2] Rehani MM. Challenges in radiation protection of patients for the 21st century. AJR Am J Roentgenol 2013;200:762-4. https://doi.org/10.2214/AJR.12.10244.

[3] Rehani MM, Srimahachota S. Skin injuries in interventional procedures. Radiat Prot Dosimetry 2011;147:8-12. https://doi.org/10.1093/rpd/ncr257.

[4] Food and Drug Administration (FDA). Initiative to Reduce Unnecessary Radiation Exposure from Medical Imaging n.d. https://www.fda.gov/radiation-emitting-p roducts/radiation-safety/initiative-reduce-unnecessary-radiation-exposure-medi cal-imaging.

[5] International Commission on Radiological Protection. Annals of the ICRP: Publication 103. Proc 31st World Nucl Assoc Annu Symp 20062007.

[6] Rehani MM. ICRP and IAEA actions on radiation protection in computed tomography. Ann ICRP 2012;41:154-60. https://doi.org/10.1016/j. icrp.2012.06.029.

[7] Kachelrieß M, Rehani MM. Is it possible to kill the radiation risk issue in computed tomography? Phys Medica 2020;71:176-7. https://doi.org/10.1016/j. ejmp.2020.02.017.

[8] M.M. Rehani T. Berris International Atomic Energy Agency study with referring physicians on patient radiation exposure and its tracking: a prospective survey using a web-based questionnaire BMJ Open 2012;2. 10.1136/bmjopen-2012001425.

[9] Rehani MM, Szczykutowicz TP, Zaidi H. CT is still not a low-dose imaging modality. Med Phys 2020;47:293-6. https://doi.org/10.1002/mp.14000.

[10] Tsapaki V, Rehani M, Saini S. Radiation Safety in Abdominal Computed Tomography. Semin Ultrasound, CT MRI 2010;31. https://doi.org/10.1053/j. sult.2009.09.004.

[11] S. Rastogi R. Singh R. Borse P.V. Zujic D. Segota A. Diklic et al. Use of Multiphase CT Protocols in 18 Countries: Appropriateness and Radiation Doses Can Assoc Radiol J = J l'Association Can Des Radiol 2020:846537119888390. 10.1177/ 0846537119888390 . 
[12] Rehani MM, Yang K, Melick ER, Heil J, Salát D, Sensakovic WF, et al. Patients undergoing recurrent CT scans: assessing the magnitude. Eur Radiol 2020;30: 1828-36. https://doi.org/10.1007/s00330-019-06523-y.

[13] Arellano R, Yang K, Rehani MM. Analysis of patients receiving $\geq 100 \mathrm{mSv}$ during a computed tomography intervention. Eur Radiol 2020. https://doi.org/10.1007/ s00330-020-07458-5.

[14] Martin CJ, Harrison JD, Rehani MM. Effective dose from radiation exposure in medicine: past, present, and future. Phys Med 2020. https://doi.org/10.1016/j. ejmp.2020.10.020.

[15] IAEA. IAEA TRS 457_Dosimetry in dignostic radiology: Code of Practice. 2007.

[16] Zoetelief J, Dance DR, Drexler G, Järvinen H, Rosenstein M, Allisy-Roberts P, et al. ICRU 74 Patient dosimetry for $\mathrm{X}$ rays used in medical imaging. J ICRU 2005; 5:1-113. https://doi.org/10.1093/jicru/ndi016.

[17] Rehani MM, Hauptmann M. Estimates of the number of patients with high cumulative doses through recurrent CT exams in 35 OECD countries. Phys Medica 2020;76:173-6. https://doi.org/10.1016/j ejmp.2020.07.014.

[18] Kalender WA, Seissler W, Klotz E, Vock P. Spiral volumetric CT with singlebreath-hold technique, continuous transport, and continuous scanner rotation. Radiology 1990;176:181-3. https://doi.org/10.1148/radiology.176.1.2353088.

[19] Rehani MM, Kalra MK, McCollough CH, Nagel HD, Collins L, Kalender W. Managing patient dose in multi-detector computed tomography(MDCT). ICRP Publication 102. Ann ICRP 2007;37(1-79):iii. https://doi.org/10.1016/j. icrp.2007.09.001.

[20] Padole AM, Sagar P, Westra SJ, Lim R, Nimkin K, Kalra MK, et al. Development and validation of image quality scoring criteria (IQSC) for pediatric CT: a preliminary study. Insights Imaging 2019;10:95. https://doi.org/10.1186/ s13244-019-0769-8.

[21] Mileto A, Nelson RC, Larson DG, Samei E, Wilson JM, Christianson O, et al Variability in radiation dose from repeat identical CT examinations: longitudinal analysis of 2851 patients undergoing 12,635 thoracoabdominal CT scans in an academic health system. AJR Am J Roentgenol 2017;208:1285-96. https://doi. org/10.2214/AJR.16.17070.

[22] Esser M, Hess S, Teufel M, Kraus MS, Schneeweiß S, Gatidis S, et al. Radiation dose optimization in pediatric chest CT: major indicators of dose exposure in 1695 CT scans over seven years. Rofo 2018;190:1131-40. https://doi.org/ 10.1055/a-0628-7222.

[23] Klink T, Obmann V, Heverhagen J, Stork A, Adam G, Begemann P. Reducing CT radiation dose with iterative reconstruction algorithms: the influence of scan and reconstruction parameters on image quality and CTDIvol. Eur J Radiol 2014;83 1645-54. https://doi.org/10.1016/j.ejrad.2014.05.033.

[24] Yu L, Primak AN, Liu X, McCollough CH. Image quality optimization and evaluation of linearly mixed images in dual-source, dual-energy CT. Med Phys 2009;36:1019-24. https://doi.org/10.1118/1.3077921.

[25] Padole A, Ali Khawaja RD, Kalra MK, Singh S. CT radiation dose and iterative reconstruction techniques. AJR Am J Roentgenol 2015;204:W384-92. https:// doi.org/10.2214/AJR.14.13241.

[26] Rehani MM, Melick ER, Alvi RM, Doda Khera R, Batool-Anwar S, Neilan TG, et al. Patients undergoing recurrent CT exams: assessment of patients with nonmalignant diseases, reasons for imaging and imaging appropriateness. Eur Radiol 2020;30:1839-46. https://doi.org/10.1007/s00330-019-06551-8.

[27] Brambilla M, Vassileva J, Kuchcinska A, Rehani MM. Multinational data on cumulative radiation exposure of patients from recurrent radiological procedures: call for action. Eur Radiol 2020;30:2493-501. https://doi.org/10.1007/s00330 019-06528-7.

[28] Rehani MM. Patient radiation exposure and dose tracking: a perspective. J Med Imaging 2017;4:031206. https://doi.org/10.1117/1.JMI.4.3.031206.

[29] Seuri R, Rehani MM, Kortesniemi M. How tracking radiologic procedures and dose helps: experience from Finland. AJR Am J Roentgenol 2013;200:771-5. https://doi.org/10.2214/AJR.12.10112.

[30] Rehani MM. Tracking of examination and dose: Overview. Radiat Prot Dosimetry 2015;165. https://doi.org/10.1093/rpd/ncv026.

[31] Rehani MM, Berris T. Templates and existing elements and models for implementation of patient exposure tracking. Radiat Prot Dosimetry 2014;158: 1-7. https://doi.org/10.1093/rpd/nct185.

[32] Rehani M, Frush D. Tracking radiation exposure of patients. Lancet 2010;376: 754-5. https://doi.org/10.1016/S0140-6736(10)60657-5.

[33] Rehani MM, Frush D, Berris T, Einstein AJ. Patient radiation exposure tracking Worldwide programs and needs - Results from the first IAEA survey. Eur J Radiol 2012;81(10):968-76. https://doi.org/10.1016/j.ejrad.2012.07.004.

[34] Mercuri M, Rehani MM, Einstein AJ. Tracking patient radiation exposure challenges to integrating nuclear medicine with other modalities. J Nucl Cardiol 2012;19:895-900. https://doi.org/10.1007/s12350-012-9586-x.

[35] Rehani MM, Berris T. Radiation exposure tracking: survey of unique patient identification number in 40 countries. AJR Am J Roentgenol 2013;200:776-9. https://doi.org/10.2214/AJR.12.10246.

[36] Murphy TP, Soares GM. The evolution of interventional radiology. Semin Intervent Radiol 2005;22:6-9. https://doi.org/10.1055/s-2005-869570.

[37] Jones AK, Dixon RG, Collins JD, Walser EM, Nikolic B. Best practice guidelines for CT-guided interventional procedures. J Vasc Interv Radiol 2018;29:518-9. https://doi.org/10.1016/j.jvir.2017.10.021.

[38] FDA. CFR - Code of Federal Regulations Title 21 n.d. https://www.accessdata.fda. gov/scripts/cdrh/cfdocs/cfcfr/CFRSearch.cfm?FR=1020.32.

[39] Bushberg J. The essential physics of medical Imaging. Philadelphia: Third. London; 2012.

[40] NCRP. NCRP Report No. 168, Radiation Dose Management for FluoroscopicallyGuided Interventional Medical Procedures. n.d.
[41] Srimahachota S, Udayachalerm W, Kupharang T, Sukwijit K, Krisanachinda A, Rehani M. Radiation skin injury caused by percutaneous coronary intervention, report of 3 cases. Int J Cardiol 2012;154:e31-3. https://doi.org/10.1016/j ijcard.2011.05.016.

[42] Tsapaki V, Rehani MM. I perform more than 100 interventional procedures every year but have never seen radiation-induced skin injury: am I missing something? Am J Roentgenol 2014;203(5):W462-3. https://doi.org/10.2214/AJR.13.11765.

[43] Tsapaki V, Balter S, Cousins C, Holmberg O, Miller DL, Miranda P, et al. The international atomic energy agency action plan on radiation protection of patients and staff in interventional procedures: achieving change in practice. Phys Medica 2018;52:56-64. https://doi.org/10.1016/j.ejmp.2018.06.634.

[44] Kostova-Lefterova D, Vassileva J, Rehani MM. Lessons from two cases of radiation induced skin injuries in fluoroscopic procedures in Bulgaria. J Radiol Prot 2017; 37:938-46. https://doi.org/10.1088/1361-6498/aa8ce7.

[45] NCRP. Statement No. 11 - Outline Of Administrative Policies For Quality Assurance And Peer Review Of Tissue Reactions Associated With Fluoroscopically-Guided Interventions. 2014.

[46] Cousins C, Miller DL, Bernardi G, Rehani MM, Schofield P, Vañó E, et al. International Commission on Radiological Protection. ICRP PUBLICATION 120: Radiological protection in cardiology. Ann ICRP 2013;42(1):1-125. https://doi. org/10.1016/j.icrp.2012.09.001.

[47] ICRP. Avoidance of Radiation Injuries from Medical Interventional Procedures. ICRP Publication 85. Ann ICRP 2000;30(2). http://www2.icrp.org/publication.as p?id=ICRP\%20Publication $\% 2085$.

[48] Rehani MM, Miller DL, Baliyan V. High dose fluoroscopically guided procedures in patients: radiation management recommendations for interventionalists. Cardiovasc Intervent Radiol 2020. https://doi.org/10.1007/s00270-020-02703 2.

[49] Balter S, Miller DL. Patient skin reactions from interventional fluoroscopy procedures. AJR Am J Roentgenol 2014;202:W335-42. https://doi.org/10.2214/ AJR.13.12029.

[50] Rehani MM. What makes and keeps radiation risks associated with CT a hot topic? Am J Roentgenol 2015;204(3):W234-5. https://doi.org/10.2214/ A.JR.14.12860.

[51] Balter S, Hopewell JW, Miller DL, Wagner LK, Zelefsky MJ. Fluoroscopically guided interventional procedures: a review of radiation effects on patients' skin and hair. Radiology 2010;254:326-41. https://doi.org/10.1148/ radiol.2542082312.

[52] Jaschke W, Bartal G, Martin CJ, Vano E. Unintended and accidental exposures, significant dose events and trigger levels in interventional radiology. Cardiovasc Intervent Radiol 2020;43:1114-21. https://doi.org/10.1007/s00270-020-025172.

[53] Tsapaki V, Faruque GM, Lim ST, Ngo Minh H, Nwe N, Sharma A, et al. Status of radiation protection in various interventional cardiology procedures in the Asia Pacific region. Heart Asia 2011;3(1):16-24. https://doi.org/10.1136/ ha.2009.001180.

[54] Pantos I, Patatoukas G, Katritsis DG, Efstathopoulos E. Patient radiation doses in interventional cardiology procedures. Curr Cardiol Rev 2009;5:1-11. https://doi. org/10.2174/157340309787048059.

[55] Li X, Hirsch JA, Rehani MM, Ganguli S, Yang K, Liu B. Radiation effective dose above $100 \mathrm{mSv}$ from fluoroscopically guided intervention: frequency and patient medical condition. Am J Roentgenol 2020:1-7. https://doi.org/10.2214/ ajr.19.22227.

[56] Sarti M, Brehmer WP, Gay SB. Low-dose techniques in CT-guided Interventions. RadioGraphics 2012;32:1109-19. https://doi.org/10.1148/rg.324115072.

[57] Bhakta D, Miller JM. Principles of electroanatomic mapping. Indian Pacing Electrophysiol J 2008;8:32-50.

[58] Scaglione M, Ebrille E, Di Clemente F, Gaita F, Bradfield JS. Catheter ablation of atrial fibrillation without radiation exposure using A 3D mapping system. J Atr Fibrillation 2015;7:1167. https://doi.org/10.4022/jafib.1167.

[59] Earley MJ, Showkathali R, Alzetani M, Kistler PM, Gupta D, Abrams DJ, et al. Radiofrequency ablation of arrhythmias guided by non-fluoroscopic catheter location: a prospective randomized trial. Eur Heart J 2006;27:1223-9. https:// doi.org/10.1093/eurheartj/ehi834.

[60] Thibault B, Mondésert B, Macle L, Dubuc M, Dyrda K, Talajic M, et al. Reducing radiation exposure during CRT implant procedures: single-center experience with low-dose fluoroscopy settings and a sensor-based navigation system (mediguide). J Cardiovasc Electrophysiol 2016;27:1337-43. https://doi.org/10.1111/ jce. 13048.

[61] Nickoloff EL, Lu ZF, Dutta A, So J, Balter S, Moses J. Influence of flat-panel fluoroscopic equipment variables on cardiac radiation doses. Cardiovasc Intervent Radiol 2007;30:169-76. https://doi.org/10.1007/s00270-006-0096-6.

[62] Lee T-Y, Chhem RK. Impact of new technologies on dose reduction in CT. Eur J Radiol 2010;76:28-35. https://doi.org/10.1016/j.ejrad.2010.06.036.

[63] Szczykutowicz TP, Bour R, Ranallo F, Pozniak M. The current state of CT dose management across radiology: well intentioned but not universally well executed. AJR Am J Roentgenol 2018;211:405-8. https://doi.org/10.2214/AJR.17.19266.

[64] Vassileva J, Rehani M, Kostova-Lefterova D, Al-Naemi HM, Al Suwaidi JS, Arandjic D, et al. A study to establish international diagnostic reference levels for paediatric computed tomography. Radiat Prot Dosimetry 2015;165(1-4):70-80. https://doi.org/10.1093/rpd/ncv116.

[65] Salama DH, Vassileva J, Mahdaly G, Shawki M, Salama A, Gilley D, et al. Establishing national diagnostic reference levels (DRLs) for computed tomography in Egypt. Phys Med 2017;39:16-24. https://doi.org/10.1016/j. ejmp.2017.05.050. 
[66] Einstein AJ, Pascual TN, Mercuri M, Karthikeyan G, Vitola JV, Mahmarian JJ, et al. INCAPS Investigators Group. Current worldwide nuclear cardiology practices and radiation exposure: results from the 65 country IAEA Nuclear Cardiology Protocols Cross-Sectional Study (INCAPS). Eur Heart J 2015;36(26): 1689-96. https://doi.org/10.1093/eurheartj/ehv117.

[67] Roch P, Célier D, Dessaud C, Etard C, Rehani MM. Long-term experience and analysis of data on diagnostic reference levels: the good, the bad, and the ugly. Eur Radiol 2020;30:1127-36. https://doi.org/10.1007/s00330-019-06422-2.

[68] Shah R, Gupta AK, Rehani MM, Pandey AK, Mukhopadhyay S. Effect of reduction in tube current on reader confidence in paediatric computed tomography. Clin Radiol 2005;60(2):224-31. https://doi.org/10.1016/j.crad.2004.08.011.

[69] Rehani MM. Radiological protection in computed tomography and cone beam computed tomography. Ann ICRP 2015;44(1 Suppl):229-35. https://doi.org/ 10.1177/0146645315575872.

[70] AlSuwaidi JS, AlBalooshi LG, AlAwadhi HM, Rahanjam A, ElHallag MA, Ibrahim JS, Rehani MM. Continuous monitoring of CT dose indexes at Dubai Hospital. AJR Am J Roentgenol 2013;201(4):858-64. https://doi.org/10.2214/ AJR.12.10233.

[71] Bogaert E, Bacher K, Lapere R, Thierens H. Does digital flat detector technology tip the scale towards better image quality or reduced patient dose in interventional cardiology? Eur J Radiol 2009;72:348-53. https://doi.org/ 10.1016/j.ejrad.2008.07.028.

[72] Trianni A, Bernardi G, Padovani R. Are new technologies always reducing patient doses in cardiac procedures? Radiat Prot Dosimetry 2005;117:97-101. https:// doi.org/10.1093/rpd/nci747.

[73] Tsapaki V, Kottou S, Kollaros N, Dafnomili P, Kyriakidis Z, Neofotistou V. Dose performance evaluation of a charge coupled device and a flat-panel digital fluoroscopy system recently installed in an interventional cardiology laboratory Radiat Prot Dosimetry 2004;111:297-304. https://doi.org/10.1093/rpd/nch344.

[74] Whitebird RR, Solberg LI, Bergdall AR, López-Solano N, Smith-Bindman R. Barriers to CT dose optimization: the challenge of organizational change. Acad Radiol 2020. https://doi.org/10.1016/j.acra.2020.02.016.

[75] Lell MM, Kachelrieß M. Recent and upcoming technological developments in computed tomography: high speed, low dose, deep learning. Multienergy Invest Radiol 2020;55:8-19. https://doi.org/10.1097/RLI.0000000000000601.

[76] Vano E. Challenges for managing the cumulative effective dose for patients. Br J Radiol 2020:20200814. https://doi.org/10.1259/bjr.20200814.

[77] Vano E. Recurrent imaging procedures with ionising radiation on the same patient. Should we pay more attention? J Radiol Prot Off J Soc Radiol Prot 2020; 40:E14-7. https://doi.org/10.1088/1361-6498/ab7fbb.

[78] Chehab MA, Brinjikji W, Copelan A, Venkatesan AM. Navigational tools for interventional radiology and interventional oncology applications. Semin Intervent Radiol 2015;32:416-27. https://doi.org/10.1055/s-0035-1564705.

[79] Mendelsohn D, Strelzow J, Dea N, Ford NL, Batke J, Pennington A, et al. Patient and surgeon radiation exposure during spinal instrumentation using intraoperative computed tomography-based navigation. Spine J 2016;16:343-54 https://doi.org/10.1016/j.spinee.2015.11.020.

[80] Rehani MM, Pauwels R, Rehani B. Evaluation of medical physics training in radiology residency in 67 countries. Phys Med 2018;54:30-3. https://doi.org/ 10.1016/j.ejmp.2018.09.006.

[81] Chen J, Einstein AJ, Fazel R, Krumholz HM, Wang Y, Ross JS, et al. Cumulative exposure to ionizing radiation from diagnostic and therapeutic cardiac imaging procedures: A population-based analysis. J Am Coll Cardiol 2010. https://doi. org/10.1016/j.jacc.2010.05.014.

[82] Einstein AJ, Weiner SD, Bernheim A, Kulon M, Bokhari S, Johnson LL, et al. Multiple testing, cumulative radiation dose, and clinical indications in patients undergoing myocardial perfusion imaging. JAMA - J Am Med Assoc 2010. https://doi.org/10.1001/jama.2010.1664.

[83] Stein EG, Haramati LB, Bellin E, Ashton L, Mitsopoulos G, Schoenfeld A, et al. Radiation exposure from medical imaging in patients with chronic and recurrent conditions. J Am Coll Radiol 2010. https://doi.org/10.1016/j.jacr.2009.12.015.
[84] Kaul P, Medvedev S, Hohmann SF, Douglas PS, Peterson ED, Patel MR. Ionizing radiation exposure to patients admitted with acute myocardial infarction in the United States. Circulation 2010. https://doi.org/10.1161/ CIRCULATIONAHA.110.973339.

[85] Eisenberg MJ, Afilalo J, Lawler PR, Abrahamowicz M, Richard H, Pilote L. Cancer risk related to low-dose ionizing radiation from cardiac imaging in patients after acute myocardial infarction. CMAJ 2011. https://doi.org/10.1503/cmaj.100463.

[86] Lawler PR, Afilalo J, Eisenberg MJ, Pilote L. Exposure to low-dose ionizing radiation from cardiac imaging among patients with myocardial infarction. Am J Cardiol 2012. https://doi.org/10.1016/j.amjcard.2011.07.065.

[87] Kinsella SM, Coyle JP, Long EB, McWilliams SR, Maher MM, Clarkson MR, et al. Maintenance hemodialysis patients have high cumulative radiation exposure. Kidney Int 2010. https://doi.org/10.1038/ki.2010.196.

[88] De Mauri A, Brambilla M, Chiarinotti D, Matheoud R, Carriero A, De Leo M. Estimated radiation exposure from medical imaging in hemodialysis patients. J Am Soc Nephrol 2011. https://doi.org/10.1681/ASN.2010070784.

[89] Coyle J, Kinsella S, McCarthy S, MacWilliams S, McLaughlin P, Eustace J, et al. Cumulative ionizing radiation exposure in patients with end stage kidney disease: A 6-year retrospective analysis. Abdom Imaging 2012. https://doi.org/10.1007/ s00261-011-9786-x.

[90] De Mauri A, Brambilla M, Izzo C, Matheoud R, Chiarinotti D, Carriero A, et al. Cumulative radiation dose from medical imaging in kidney transplant patients. Nephrol Dial Transplant 2012. https://doi.org/10.1093/ndt/gfs145.

[91] Desmond AN, McWilliams S, Maher MM, Shanahan F, Quigley EM. Radiation exposure from diagnostic imaging among patients with gastrointestinal disorders. Clin Gastroenterol Hepatol 2012. https://doi.org/10.1016/j.cgh.2011.11.007.

[92] Levi Z, Fraser A, Krongrad R, Hazazi R, Benjaminov O, Meyerovitch J, et al. Factors associated with radiation exposure in patients with inflammatory bowel disease. Aliment Pharmacol Ther 2009. https://doi.org/10.1111/j.13652036.2009.04140.x.

[93] Kroeker KI, Lam S, Birchall I, Fedorak RN. Patients with IBD are exposed to high levels of ionizing radiation through CT scan diagnostic imaging: a five-year study. J Clin Gastroenterol 2011. https://doi.org/10.1097/MCG.0b013e3181e5d1c5.

[94] Butcher RO, Nixon E, Sapundzieski M, Filobbos R, Limdi JK. Radiation exposure in patients with inflammatory bowel diseaseprimum non nocere? Scand J Gastroenterol 2012. https://doi.org/10.3109/00365521.2012.706829.

[95] Estay C, Simian D, Lubascher J, Figueroa C, O'Brien A, Quera R. Ionizing radiation exposure in patients with inflammatory bowel disease: are we overexposing our patients? J Dig Dis 2015. https://doi.org/10.1111/1751 2980.12213.

[96] Chatu S, Poullis A, Holmes R, Greenhalgh R, Pollok RCG. Temporal trends in imaging and associated radiation exposure in inflammatory bowel disease. Int $\mathrm{J}$ Clin Pract 2013. https://doi.org/10.1111/ijcp.12187.

[97] Jung YS, Il Park D, Kim ER, Kim YH, Lee CK, Lee SH, et al. Quantifying exposure to diagnostic radiation and factors associated with exposure to high levels of radiation in korean patients with inflammatory bowel disease. Inflamm Bowel Dis 2013. https://doi.org/10.1097/MIB.0b013e31828c844f.

[98] Fuchs Y, Markowitz J, Weinstein T, Kohn N, Choi-Rosen J, Levine J. Pediatric inflammatory bowel disease and imaging-related radiation: are we increasing the likelihood of malignancy? J Pediatr Gastroenterol Nutr 2011. https://doi.org/ 10.1097/MPG.0b013e3181f57177.

[99] Sauer CG, Kugathasan S, Martin DR, Applegate KE. Medical radiation exposure in children with inflammatory bowel disease estimates high cumulative doses. Inflamm Bowel Dis 2011. https://doi.org/10.1002/ibd.21626.

[100] Huang JS, Tobin A, Harvey L, Nelson TR. Diagnostic medical radiation in pediatric patients with inflammatory bowel disease. J Pediatr Gastroenterol Nutr 2011. https://doi.org/10.1097/MPG.0b013e31820d5d84.

[101] Brambilla M, Cerini P, Lizio D, Vigna L, Carriero A, Fossaceca R. Cumulative radiation dose and radiation risk from medical imaging in patients subjected to endovascular aortic aneurysm repair. Radiol Medica 2015. https://doi.org/ 10.1007/s11547-014-0485-x. 